of the whole problem. There is an eminently practical note in the whole pamphlet, and if a word of criticism is called for, it is that the bibliography, even within the limits set, might have been improved.

\section{The Cooper Union: Annual Report}

The report of the Director of the Cooper Union, of New York, for the year ending June 30, 1944, covering the eighty-fifth year of the Institution, indicates that, although in some respects the disturbance of education in the United States under the impact of war has been less profound than in Great Britain, the problems of demobilization and of retraining are being faced along similar lines. There is an interesting parallel between educational thought, as portrayed in this report, in the two countries. Stress is laid upon the necessity of finding a strong and socially satisfying ethical foundation for modern education, on the limitations of the scientific method, and on the importance of no longer confining instruction and discussion in the human and spiritual values to the level of higher education and the liberal arts. The humanities and the social sciences should be brought into the curriculum of the high school, vocational school, junior college, technical institute and engineering school. The Department of Humanities of the Union has been successfully experimenting since 1939 with the integration of social and humanistic studies with the curricula of the schools of engineering and art, and is now offering a sequence of studies which, taken as a whole, should give a perspective of the history of Western culture and an appreciation of their roles as citizens and as individuals.

The report recognizes that the professional world of engineering and art properly demands a breadth and depth of preparation and a sophistication which cannot be gained by conventional class-room routine. The Cooper Union has been able to keep the nucleus of the teaching staff of its School of Engineering reasonably close to normal in the war period, and resumption of full teaching loads after the War can therefore be undertaken with speed and efficiency and with only minor additions to the staff. Policies to be followed with regard to the re-training of the demobilized and their integration into academic and social life are indicated, and a sub-committee of the Engineering Faculty has set itself the task of determining those qualities and attributes which should characterize the products of the four engineering curricula. Reference is also made to the work of the Student Health Service in educating the student in the use of the facilities already existing in the surrounding community, and of the Division of Social Philosophy, which completed its first decade during the year, in the field of adult education.

\section{Museums and Adult Education}

Av editorial article in the Australian Museum Magazine (June-August, 1944) directs attention to the contribution which museums have already made towards adult education. At the same time, it points out that there still remains the necessity for far greater extensions of the museums' services in this direction. It is suggested, for example, that museums should be available to the public out of ordinary working hours; that there should be better accommodation for study; and that there should be an increase of suitably qualified staff to guide and assist students.

\section{Society of Public Analysts and Other Analytical Chemists}

THE annual general meeting of the Society of Public Analysts and Other Analytical Chemists, held on March 9, marked the seventieth anniversary of the Society. In the past year the membership of the Society increased by 117 to 1,197 , and the circulation of the Society's journal, the Analyst, in spite of paper restriction, increased. In pursuance of the policy decided upon a year ago, the Society recently formed, within the framework of its constitution, two Groups concerned with particular branches of analysis, namely, the Microchemistry Group (chairman, Prof. H. V. A. Briscoe; hon. secretary, Mr. R. Belcher; present membership, 143) and the Physical Methods Group (chairman, Mr. R. C. Chirnside; hon. secretary, Dr. F. Wokes; present membership, 115). These Groups will hold meetings from time to time in London and elsewhere. The proceedings terminated with the presidential address of the retiring president, Mr. S. Ernest Melling, who, after reviewing some of the outstanding events of the past year in the Society's affairs, made some observations on the subject of water and water supplies. Dr. G. W. MonierWilliams was elected president for the present year.

\section{Science Masters' Association: Annual Meeting}

THE annual meeting of the Science Masters' Association will be held during April 9-11 at the City of London School. The president, Mr. C. L. Bryant, will speak on "The Impact of Science on Common Thought". The proceedings will include lectures by Dr. J. McG. Bruckshaw on "Physics and Economic Geology"; Mr. C. Bibby on "Health Education through School Biology"; "Penicillin", by Sir Alexander Fleming; "Scope and Limitations of the Science Teaching Film", by Mr. A. Elton (at the Ministry of Information Theatre); "The Electron Microscope", by Mr. F. W. Cuckow; "Chemistry of Plastics", by Mr. R. Maitland; and a discussion on "The Role of Science in the Future Educational System". There will also be the usual exhibitions. The third lecture on the Science and Citizenship Foundation will be delivered by Mr. J. G. Crowther, who will speak on "The Social Relations of Science" ; this lecture is open to the public, and tickets for visitors can be obtained from Mr. W. Ashhurst, Epsom College, Surrey.

\section{Announcements}

The Bristol Aeroplane Company has given $£ 60,000$ to the University of Bristol for the establishment of a Sir George White chair of aeronautical engineering, in memory of the founder of the Company.

THE Biochemical Society and the Nutrition Society have arranged a joint whole-day conference on "The Vitamin B-Complex", to be held on April 28, at the London School of Hygiene and Tropical Medicine, Keppel Street, W.C.1. Details of the programme will be published later.

Prof. James Mackintosh, dean of the London School of Hygiene and Tropical Medicine, is visiting Sweden to lecture for the British Council on aspects of social medicine and health education in Britain. He will probably also visit Finland. Prof. Mackintosh hopes to obtain in Sweden information for inclusion in a report on housing which he is preparing for the British Government. 